Surgeon

Elsevier Editorial system(tm) for The

Manuscript Draft

Manuscript Number: SURGE-D-18-00003

Title: Configuration of the extra-renal venous system in relation to the left renal vein: a cadaveric study and new proposed classification.

Article Type: Original Article

Keywords: inferior vena cava; lumbar vein; left renal vein; anatomy; renal transplantation

Corresponding Author: Mr. Alexander Walker,

Corresponding Author's Institution: Addenbrooke's Hospital

First Author: Alexander Walker

Order of Authors: Alexander Walker; Naim Slim; Michael Nicholson; Cecilia Brassett

Abstract: The advent of laparoscopic live-donor nephrectomy for renal transplantation has prompted the need to define the precise anatomical relations of the left renal vein (LRV) and its tributaries. The left kidney is preferred as the greater LRV length facilitates implantation in the recipient. While previous studies have described variations in the LRV system, the connections between the left ascending lumbar vein (LALV) and LRV tributaries have been less well-defined. This study further characterises the LALV and proposes a novel classification for its relation to the LRV.

Dissection of the LRV system, including the left suprarenal vein (LSV), left gonadal vein (LGV) and LALV, was performed in 38 cadavers. Their drainage points into the LRV were recorded, and measurements taken of the distances from these points to the junction of the LRV and inferior vena cava (IVC).

A direct connection between the LALV and LRV was identified in 32 (86\%) cases. The drainage point of the LALV into the LRV lay between the IVC and LGV in 8 (25\%) cases. In 20 cases (63\%), the drainage points of the LALV and LGV were equidistant from the IVC; in 5 cases (16\%), those of the LALV and posterior branch of the LRV were equidistant from the IVC. In these two groups, the vessels shared a confluent trunk in 10 and 4 cases respectively. In 3 cases, connections were observed between all three vessels (LALV, LGV and posterior branch of LRV). No confluence was shared by the LALV and LSV.

Our results confirm the high incidence of communicating LALVs, which represent a potentially troublesome source of operative bleeding if unrecognised. Confluent venous trunks may also present difficulties during vessel ligation prior to nephrectomy. Our novel classification of the relation of the LALV to the LRV may assist in surgical planning and reduce complications.

Suggested Reviewers: 



\section{Configuration of the extra-renal venous system in relation to the left renal vein: a cadaveric study and new proposed classification.}

This article describes cadaveric research carried out over one academic year at the Department of Physiology, Development and Neurosciences, University of Cambridge.

The existence of lumbar veins and their communications with the left renal vein are well recognised. They can be a troublesome source of bleeding intraoperatively, particularly when using an anterior laparoscopic approach to access the left kidney, due to the posterior confluence of these vessels. In our experience, there is an under-appreciation of these vessels by trainee surgeons, and they are often not described in radiological pre-operative scan reports.

Our research uniquely characterises the relation of the lumbar veins to other tributaries of the left renal vein and offers a simple classification system, informed by developmental studies.

We expect our classification system could be used to describe radiological findings pre-operatively, inform surgical planning and alert the surgeon to the likely location of a lumbar vein. We are currently working on radiological correlation for our classification system.

Future research will also focus on the occurrence of post-operative testicular congestion and pain, which is an under-reported consequence of left kidney donation, in relation to donor anatomy and level of left renal and gonadal vein tieoff. This could have an impact on surgical technique and offer potential live kidney donors a more personalised risk assessment and consent process. 
Title:

Configuration of the extra-renal venous system in relation to the left renal vein: a cadaveric study and new proposed classification.

1. Mr Alexander Walker Department of Surgery

University of Cambridge

Cambridge, UK

2. Dr Naim Slim

Human Anatomy Teaching Group

Department of Physiology, Development and Neurosciences

University of Cambridge, Downing Street

Cambridge, UK

3. Prof Michael Nicholson

Department of Surgery

University of Cambridge

Cambridge, UK

4. Dr Cecilia Brassett

Human Anatomy Teaching Group

Department of Physiology, Development and Neurosciences

University of Cambridge

Cambridge, UK 
Configuration of the extra-renal venous system in relation to the left renal vein: a cadaveric study and new proposed classification.

\section{ABSTRACT}

The advent of laparoscopic live-donor nephrectomy for renal transplantation has prompted the need to define the precise anatomical relations of the left renal vein (LRV) and its tributaries. The left kidney is preferred as the greater length of the LRV facilitates implantation in the recipient. While previous studies have described variations in the LRV system, the connections between the left ascending lumbar vein (LALV) and LRV tributaries have been less well-defined. This study aims to further characterise the LALV and proposes a novel classification for its relation to other veins.

Dissection of the LRV system, including the left suprarenal vein (LSV), left gonadal vein (LGV) and LALV, was performed in 38 cadavers. Their drainage points into the LRV were recorded, and measurements taken of the distances from these points to the junction of the LRV and inferior vena cava (IVC).

The position of the LRV in relation to the aorta was anterior in 35 cases (92\%), entirely posterior in 1 case (3\%), and circumaortic in 2 cases (5\%). Duplication of the LSV and LGV occurred in $6(16 \%)$ and $10(27 \%)$ cases respectively. A direct posterior connection between the LALV and LRV was identified in $32(86 \%)$ cases. The drainage point of the LALV into the LRV lay between the IVC and LGV in 8 (25\%) cases. In 20 cases (63\%), the drainage points of the LALV and LGV were equidistant from the IVC; and in 5 cases (16\%), those of the LALV and posterior branch of the LRV were equidistant from the IVC. In these two groups, the vessels shared a confluent trunk in 10 and 4 cases respectively. In 3 cases, connections were observed between all three vessels (LALV, LGV and posterior branch of LRV). No confluence trunk was shared by the LALV and LSV.

These results confirm the high incidence of communicating LALVs, which represent a potentially troublesome source of operative bleeding if unrecognised. Confluent venous trunks may also present difficulties during vessel ligation prior to nephrectomy. It is 
suggested that a novel classification of the relation of the LALV based on these findings may assist in surgical planning and reduce complications.

\section{Keywords:}

inferior vena cava; lumbar vein; left renal vein; anatomy; renal transplantation 


\section{INTRODUCTION}

The last 20 years have seen radical changes to the surgical technique for live donor nephrectomy. The traditional approach to donor nephrectomy involved an open operation through a large loin incision, often with resection of the $12^{\text {th }}$ rib. This was associated with significant morbidity and a prolonged convalescence time. Open surgery has been superseded by hand-assisted and fully laparoscopic methods, performed through either a transperitoneal or a retroperitoneal approach (Ratner et al, 1995, Wright et al 2008, Nicholson et al 2010). Laparoscopic nephrectomy can also be performed through a single trans-umbilical incision (Gill et al 2008). These new advances are not without risk, in particular the need for stringent haemostasis to avoid emergency conversion to open surgery. A particular challenge is the high variability in posterior abdominal veins, especially the presence of potentially hazardous lumbar veins communicating with the left renal vein (Leventhal et al, 2000; Leventhal et al 2004, Gill et al 2007, Simon et al 2004). If these vessels are divided without secure ligation they are prone to retraction into the prevertebral fat with potentially serious morbidity from venous bleeding (Martay et al, 2003).

Previous studies have described the incidence of lumbar or ascending lumbar veins in communication with the left renal vein. These studies have relied on either cadaveric (Baniel et al, 2005; Ballesteros et al 2014; Satyapal et al, 1994; Raheem et al, 2008), radiological (Turkvatan et al, 2009; Cinar et al, 2016; Zhu et al, 2015; Dilli et al, 2012 \& 2013; Lewis et al, 2004; Yao et al, 2003), or operative findings (Batista-silva et al, 1997) in healthy and diseased states. Although a wide range of variation has been described in the lumbar venous system, less attention has been given to the pattern of venous blood drainage from the lumbar tributaries into the left renal vein.

The aim of this study was to describe the incidence of lumbar tributaries of the left renal vein and their relations to other left renal vein tributaries in a series of cadaveric dissections. We propose a classification system, borne out by embryological studies, which aims to assist the 
transplant and urological surgeon in planning and performing laparoscopic surgery on the left kidney.

\section{METHODS}

All donors provided informed consent for education and research in line with the Human Tissue Act 2004.

Dissection of the left renal vein (LRV) system, including the left suprarenal vein (LSV), left gonadal vein (LGV) and left lumbar vein (LLV), was performed in 41 cadavers. Two assessors recorded the drainage points of these veins into the LRV. Veins were considered to drain into the LRV at the same point if their confluence with the LRV overlapped.

Measurements were taken of the distances from the medial aspect of each LRV tributary to the junction of the LRV and inferior vena cava (IVC), as well as the distance from the renal pelvis to the IVC. Measurements were taken in triplicate using handheld callipers (Manufacturer's details?).

\section{RESULTS}

Three cases were excluded due to retroperitoneal disease involving the left renal vein.

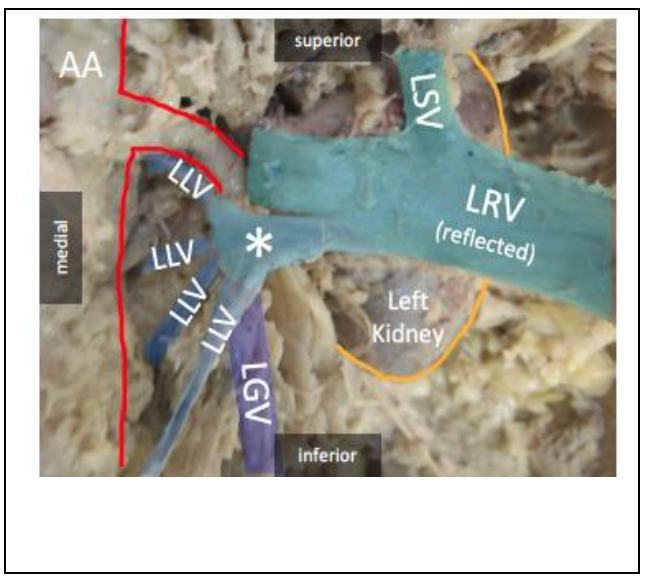


The LRV lay anterior to the aorta in $92 \%(\mathrm{n}=35)$, entirely posterior in $3 \%(\mathrm{n}=1)$ and circumaortic in $5 \%(\mathrm{n}=2)$ of cases. An additional LSV was found in $16 \%(\mathrm{n}=6)$ and an additional LGV in $26 \%(n=10)$ of cases.
Figure 1: Annotated dissected specimen (enterior view with reflected $L R V)$, showing an example of confluent trunk between $L L V$ and $L G V . *$ confluent trunk

A communicating LV was identified in $84 \%(n=32)$ of cases, consistently draining into the posterior aspect of the left renal vein. When present, it drained between the LGV and IVC in $25 \%(\mathrm{n}=8)$, at the level of the $\mathrm{LGV}$ in $63 \%(\mathrm{n}=20)$ and at the level of the posterior renal vein (PRV) in $16 \%(\mathrm{n}=5)$ of cases. When draining at the level the GV or PRV, the vessels shared a confluent trunk in $50 \%(10 / 20)$ and $80 \%(4 / 5)$ of cases. Clear vascular connections between LGV, LLV and PRV were observed in three cases. There were no instances of LV sharing a confluent trunk with the AV.

The mean distance between IVC and left kidney was 80mm (range 58-113mm). Mean distance from IVC to adrenal vein was $32 \mathrm{~mm}$ (range $20-49 \mathrm{~mm}$ ), IVC to gonadal vein $38 \mathrm{~mm}$ (range 21-60mm), IVC to lumbar vein $36 \mathrm{~mm}$ (range 20-58). The mean distance ratio (IVC to LRV tributary over entire LRV length) was 0.40 for adrenal vein, 0.48 for gonadal vein, and 0.44 for lumbar vein.

Based on our observations, we offer the following classification system for the relation between left lumbar vein and left renal vein: 


\begin{tabular}{|l|l|}
\hline I & No connection between LV and \\
& LRV \\
\hline II (c) & LV draining at the level of PRV \\
\hline III (c) & LV draining at the level of GV \\
\hline IV & LV draining between GV and IVC \\
\hline V & Confluence of GV, LV and PRV \\
& \\
\hline
\end{tabular}

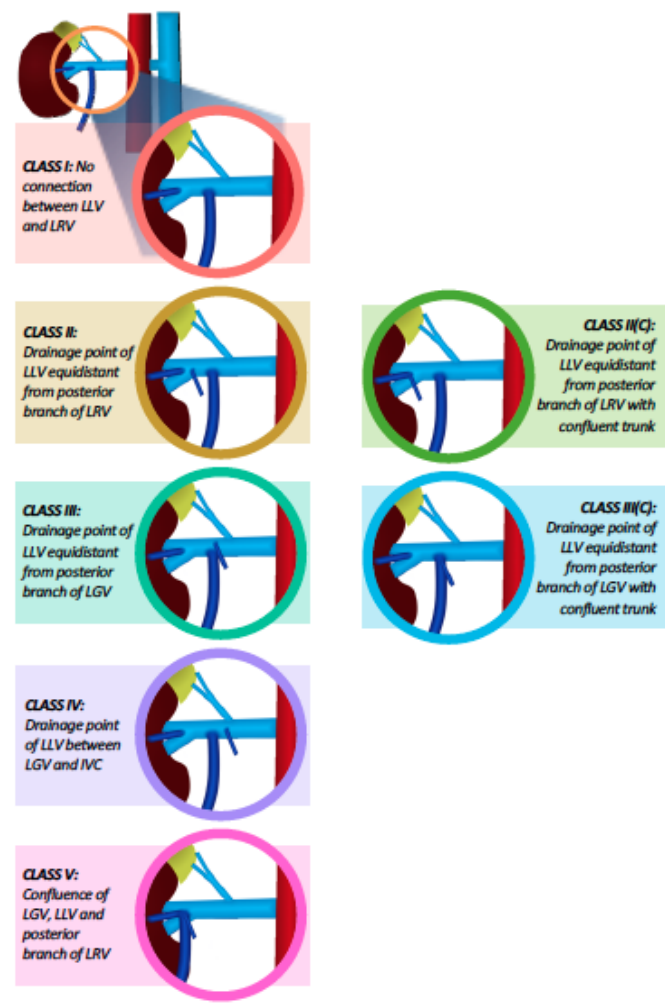

(c) confluent trunk.

Table 1: Proposed left lumbar vein classification Figure 2: Illustrated classification

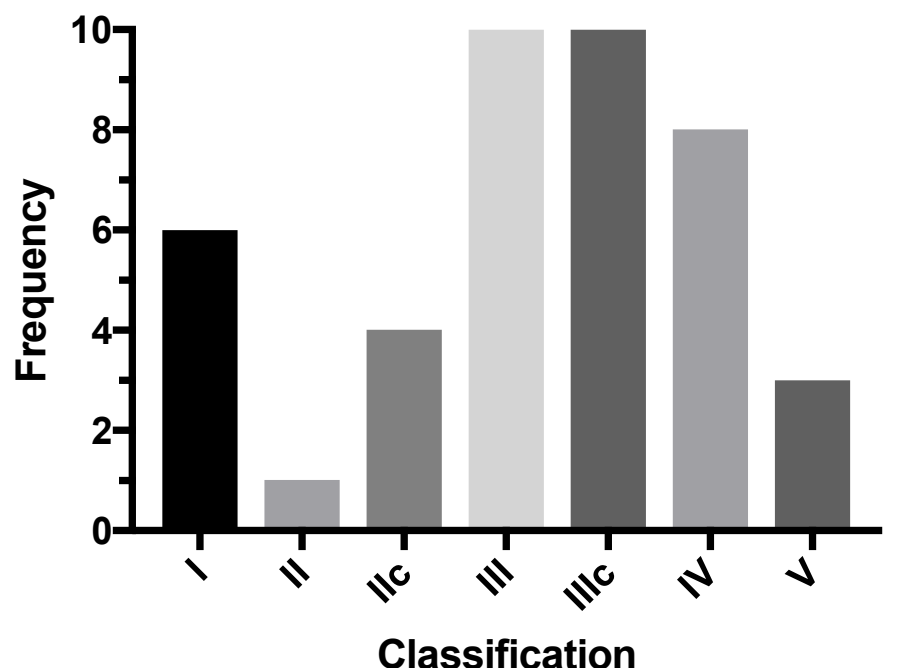

Table 2: Frequency chart for the proposed left lumbar vein classification

\section{DISCUSSION}




\section{Review of the Embryology}

A detailed study of the IVC drainage pattern was first carried out on a series of cat and human embryos in the early twentieth century (Huntingdon and McClure, 1920; McClure and Butler, 1925; Butler, 1927). The most significant transformations in the IVC system are observed in embryos between 10 and $18 \mathrm{~mm}$ in length. Before then, a symmetrical venous system of posterior cardinal veins and anterior subcardinal veins drains the majority of the blood below the diaphragm back to the heart, with numerous anastomoses between the two.

The IVC forms from three separate venous systems which develop in sequence: the subcardinal veins, the supracardinal veins and posterior cardinal veins, which ultimately lead to the formation of prerenal IVC, postrenal IVC and iliac confluence respectively.

The beginnings of an asymmetrical arrangement to the pre-renal IVC is seen in $11 \mathrm{~mm}$ embryos as a confluence of hepatic sinusoids, caval mesentery vein and a portion of the right subcardinal vein. A network of anastomotic channels also appear between the right and left subcardinal veins which will later give rise to the left renal vein, and between the right and left posterior cardinal veins in the iliac region.

The asymmetrical arrangement continues with the atrophy of the left posterior cardinal vein and confluence of the anastomotic channels between the right and left subcardinal veins, shifting venous return from the left to the right side of the body. 
The supracardinal veins develop by the $15 \mathrm{~mm}$ embryonic stage. These veins appear separately dorsolateral to the aorta in the thoracic and lumbar region. They ultimately contribute to the establishment of the azygos and hemi-azygos veins. In addition, the right supracardinal vein forms the post-renal section of the IVC.

The thoracic supracardinal veins receive segmental venous drainage from the body wall. The lumbar supracardinal vessels extend

Figure 3: Diagram of the venous
system of a 22-mm human
embryo. From McClure et al,
1927. With permission from
wilen
venous system of a 22-mm
al, 1927. With permission from
Wiley
longitudinally up to the level of the intersubcardinal anastomosis (later to become the left renal vein), and have numerous anastomoses with the posterior cardinal system.

Important anastomoses appear along the medial surface of each embryological metanephros; Connections between the subcardinal, supracardinal and posterior cardinal systems as well as the intersubcardinal anastomoses form part of the embryonic renal collar, a circumaortic venous ring which exists at the level of the developing left renal vein. The abnormal persistence of this ring into adult life gives rise to circumaortic left renal vein.

The left supracardinal vein which gives rise to the left lumbar and hemiazygos venous system remains distinct and does not contribute to the post-renal portion of IVC. It does however indirectly communicate with the IVC through the circumaortic venous ring. 
Portions of the adrenal veins are clearly described by McClure as arising from the subcardinal veins, draining directly into the pre-renal division of the IVC on the right, and into the subcardinal anastomosis on the left. The right adrenal vein drains through several small veins to the subcardinal part of the IVC, whereas one large adrenal vein usually drains the left gland to the subcardinal anastomosis.

By contrast, the gonadal veins are not clearly visible until the $20 \mathrm{~mm}$ embryological stage, which represents a late stage of IVC development. By this point the standard asymmetrical configuration of the IVC has already been reached. Prior to this stage of development the gonads are seen opening into small veins draining the mesonephros. These veins are usually described as directly draining into the subcardinal veins. However, as described and illustrated by McClure et al, the gonadal veins drain to the cardinal vein both directly, and indirectly through the subsupracardinal anastomosis (Figures 3 and 4). This embryological relation of the gonadal veins to both the sub- and supra-cardinal system forms the basis of multiple observations that link the gonadal and lumbar veins (Li et al 2011, Gillot et al 2008, Baniel et al 1995). This same drainage pattern features in other embryological studies (McClure and Butler 1925, Butler 1927). Crucially these junctions are situated caudal to the circumaortic venous ring.

Furthermore, in their reconstructed print and diagrams from the $22 \mathrm{~mm}$ embryonic stage, both the right and left sided renal veins consist of an anterior vein draining to the subcardinal system, and a posterior renal vein draining to the supracardinal system.

Our observations in this cadaveric study suggest a variable relationship between the left renal vein, lumbar / azygos system, gonadal vein, and posterior renal vein. The embryological 
development of these veins provides a basis for these observed relations. The adrenal vein remains distinct and drains directly to the left renal vein, and our observations confirm the absence of a predictable relationship between the adrenal and lumbar veins.

\section{Clinical Work and Classifications}

Our work proposes a novel classification system for the left lumbar vein in relation to the left renal vein. Prior work by $\mathrm{Li}$ et al. (Li et al, 2011) has suggested a classification system (Types 1 to 7) based on operative findings in a case series of 61 left kidney live donor nephrectomies. Their classification system recognises the existence of connections between gonadal and lumbar veins, but not with the posterior renal vein, and places an emphasis on the direction of travel as well as the number of lumbar veins, thus aiding surgical planning. However, their classification does not focus on the lumbar vein drainage point relative to other left renal vein tributaries; by emphasising the direction and number of lumbar vessels it also exposes itself to deficiencies in an area with high venous variability, and indeed to our knowledge the classification has not been validated in further work.

Raheem et al performed cadaveric dissection of 11 pairs of kidneys and their vasculature and confirmed a high prevalence of lumbar veins communicating with the left renal vein (10/11, 91\%). They make the observation that in half the specimens, the LLV drained into the LRV, at a point midway along a diagonal line between the site of entry of the LAV and LGV; The LLV in the other specimens differed and entered the posterior surface of the LRV opposite either the LAV or LGV (Raheem et al, 2008). Although our observations concur that the left lumbar vein drains on the posterior surface of the left renal vein, we found no pattern of relation between the lumbar vein and the adrenal vein. In particular there were no instances 
of a confluent trunk between the lumbar and adrenal veins. This is also borne out by the embryology and development of the IVC and renal vessels described above.

Routine radiological pre-operative assessment does not obviate the need for a keen appreciation of renal vasculature, including the lumbar vein: Rydberg et al reported that in 52 patients, 12 vascular variants not reported in the planning CT were found intraoperatively. This included 9 venous variants, of which at least 4 involved lumbar veins.

\section{$\underline{\text { A new Classification System }}$}

Our study confirms the high incidence of communicating lumbar veins, which is often under appreciated and is a potentially troublesome source of operative bleeding. Our observations of confluent trunks between LLV, GV and PRV suggest a close relationship between these vessels, which was not observed between LLV and AV. This is borne out by other groups' observations and by the embryology of the IVC system. We propose a 5-part classification system to the relationship between the left lumbar vein and left renal vein.

Our classification system does not take into account whether the lumbar vein is ascending, descending, part of a circumaortic venous ring, part of a retroaortic network, or a combination of these. The high variability of these vessels would make such a system too complex to provide helpful information, and our emphasis is on the drainage point of the lumbar vessels into the left renal vein and its relation to other tributaries. Rather than providing an exhaustive system it aims to help surgical planning in the retroaortic and transperitoneal laparoscopic approaches to the left renal vein, by focussing on the point of contact between lumbar vessels and left renal vein.

\section{CONCLUSION}


This cadaveric study identifies five distinct patterns of venous drainage between the left lumbar vein, left renal vein and its tributaries. The classification system is simple and provides structure to an area of great venous complexity and variation. We envisage it will prove helpful for laparoscopic approaches to the left kidney.

Further studies are needed to validate our classification system both radiologically and in surgical practice. 


\section{REFERENCES}

1. Ratner LE, Ciseck LJ, MooRE RG, Cigarroa FG, Kaufman HS, Kavoussi LR. Laparoscopic live donor nephrectomy. Transplantation-Baltimore. 1995 Nov 15;60(9):1047-9.

2. Wright AD, Will TA, Holt DR, Turk TM, Perry KT. Laparoscopic living donor nephrectomy: a look at current trends and practice patterns at major transplant centers across the United States. The Journal of urology. 2008 Apr 30;179(4):1488-92.

3. Nicholson ML, Kaushik M, Lewis GR, Brook NR, Bagul A, Kay MD, Harper SJ, Elwell R, Veitch PS. Randomized clinical trial of laparoscopic versus open donor nephrectomy. British Journal of Surgery. 2010 Jan 1;97(1):21-8.

4. Gill IS, Canes D, Aron M, Haber GP, Goldfarb DA, Flechner S, Desai MR, Kaouk JH, Desai MM. Single port transumbilical (E-NOTES) donor nephrectomy. The Journal of urology. 2008 Aug 31;180(2):637-41.

5. Leventhal JR, Deeik RK, Joehl RJ, Rege RV, Herman CH, Fryer JP, Kaufman D, Abecassis M, Stuart FP. LAPAROSCOPIC LIVE DONOR NEPHRECTOMY - IS IT SAFE?: Analysis of 80 Consecutive Cases and Comparison with Open Nephrectomy. Transplantation. 2000 Aug 27;70(4):602-6.

6. Leventhal JR, Kocak B, Salvalaggio PR, Koffron AJ, Baker TB, Kaufman DB, Fryer JP, Abecassis MM, Stuart FP. Laparoscopic donor nephrectomy 1997 to 2003 : lessons learned with 500 cases at a single institution. Surgery. 2004 Oct 31;136(4):881-90.

7. Gill IS, Kavoussi LR, Lane BR, Blute ML, Babineau D, Colombo JR, Frank I, Permpongkosol S, Weight CJ, Kaouk JH, Kattan MW. Comparison of 1,800 laparoscopic and open partial nephrectomies for single renal tumors. The Journal of urology. 2007 Jul 31;178(1):41-6. 
8. Simon SD, Castle EP, Ferrigni RG, Lamm DL, Swanson SK, Novicki DE, Andrews PE. Complications of laparoscopic nephrectomy: the Mayo clinic experience. The journal of urology. 2004 Apr 30;171(4):1447-50.

9. Martay K, Dembo G, Vater Y, Charpentier K, Levy A, Bakthavatsalam R, Freund PR. Unexpected surgical difficulties leading to hemorrhage and gas embolus during laparoscopic donor nephrectomy: a case report. Canadian Journal of Anesthesia/Journal canadien d'anesthésie. 2003 Nov 1;50(9):891-4.

10. Baniel J, Foster RS, Donohue JP. Surgical anatomy of the lumbar vessels: implications for retroperitoneal surgery. The Journal of urology. 1995 May 31;153(5):1422-5.

11. Ballesteros LE, Saldarriaga V, Ramirez LM. Morphologic evaluation of the renal veins: a study with autopsy material from Colombian subjects. Rom J Morphol Embryol. 2014;55(1):77-81.

12. Satyapal KS, Kalideen JM. The left renal vein: a major collateral system. Clinical Anatomy. 1994 Jan 1;7(6):352-6.

13. Raheem OA, O’Brien M, Glacken P, Mohan P, Hickey DP. A review of the anatomical variations of the posterior tributaries of the left renal vein. Irish journal of medical science. 2008 Mar 1;177(1):59-62.

14. Türkvatan A, Özdemir M, Cumhur T, Ölçer T. Multidetector CT angiography of renal vasculature: normal anatomy and variants. European radiology. 2009 Jan 1;19(1):23644.

15. Çınar C, Türkvatan A. Prevalence of renal vascular variations: evaluation with MDCT angiography. Diagnostic and interventional imaging. 2016 Sep 30;97(9):891-7.

16. Zhu J, Zhang L, Yang Z, Zhou H, Tang G. Classification of the renal vein variations: a study with multidetector computed tomography. Surgical and Radiologic Anatomy. 2015 Aug 1;37(6):667-75. 
17. Dilli A, Ayaz UY, Karabacak OR, Tatar IG, Hekimoglu B. Study of the left renal variations by means of magnetic resonance imaging. Surgical and radiologic anatomy. 2012 Apr 1;34(3):267-70.

18. Dilli A, Ayaz UY, Kaplanoğlu H, Saltas H, Hekimoglu B. Evaluation of the left renal vein variations and inferior vena cava variations by means of helical computed tomography. Clinical imaging. 2013 Jun 30;37(3):530-5.

19. Lewis GR, Mulcahy K, Brook NR, Veitch PS, Nicholson ML. A prospective study of the predictive power of spiral computed tomographic angiography for defining renal vascular anatomy before live- donor nephrectomy. BJU international. 2004 Nov 1;94(7):1077-81.

20. Yao Y, Okada Y, Yamato M, Ohtomo K. Communicating vein between the left renal vein and left ascending lumber vein: incidence and significance on abdominal CT. Radiation medicine. 2003 Nov 1;21(6):252-7.

21. Baptista-Silva JC, Veríssimo MJ, Castro MJ, Câmara AL, Pestana JO. Anatomical study of the renal veins observed during 342 living-donor nephrectomies. Sao Paulo Medical Journal. 1997 Jun;115(3):1456-9.

22. Huntington GS, McClure CF. The development of the veins in the domestic cat (Felis domestica) with especial reference, 1) to the share taken by the supracardinal veins in the development of the postcava and azygos veins and 2) to the interpretation of the variant conditions of the postcava and its tributaries, as found in the adult. The Anatomical Record. 1920 Dec 1;20(1):1-30.

23. McClure CF, Butler EG. The development of the vena cava inferior in man. Developmental Dynamics. 1925 Jul 1;35(3):331-83.

24. Butler EG. The relative role played by the embryonic veins in the development of the mammalian vena cava posterior. Developmental Dynamics. 1927 May 1;39(2):267353. 
25. Li G, Dong J, Lu JS, Zu Q, Yang SX, Li HZ, Ma X, Zhang X. Anatomical variation of the posterior lumbar tributaries of the left renal vein in retroperitoneoscopic left living donor nephrectomy. International Journal of Urology. 2011 Jul 1;18(7):503-9. 


\begin{tabular}{|l|l|}
\hline I & $\begin{array}{l}\text { No connection between LV and } \\
\text { LRV }\end{array}$ \\
\hline II (c) & LV draining at the level of PRV \\
\hline III (c) & LV draining at the level of GV \\
\hline IV & LV draining between GV and IVC \\
\hline V & Confluence of GV, LV and PRV \\
& \\
\hline
\end{tabular}

Table 1: Proposed left lumbar vein classification 


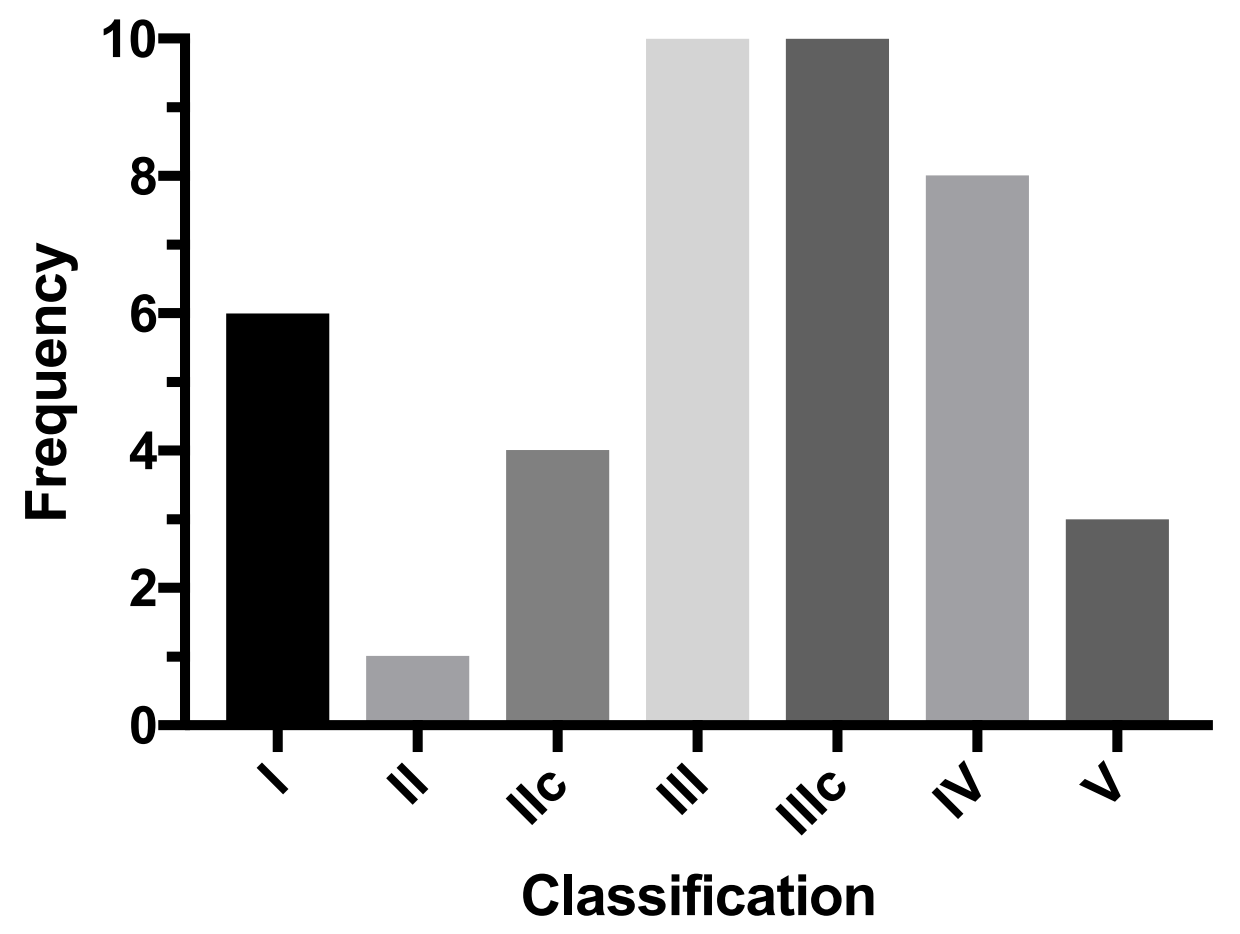

Table 2: Frequency chart for the proposed left lumbar vein classification 


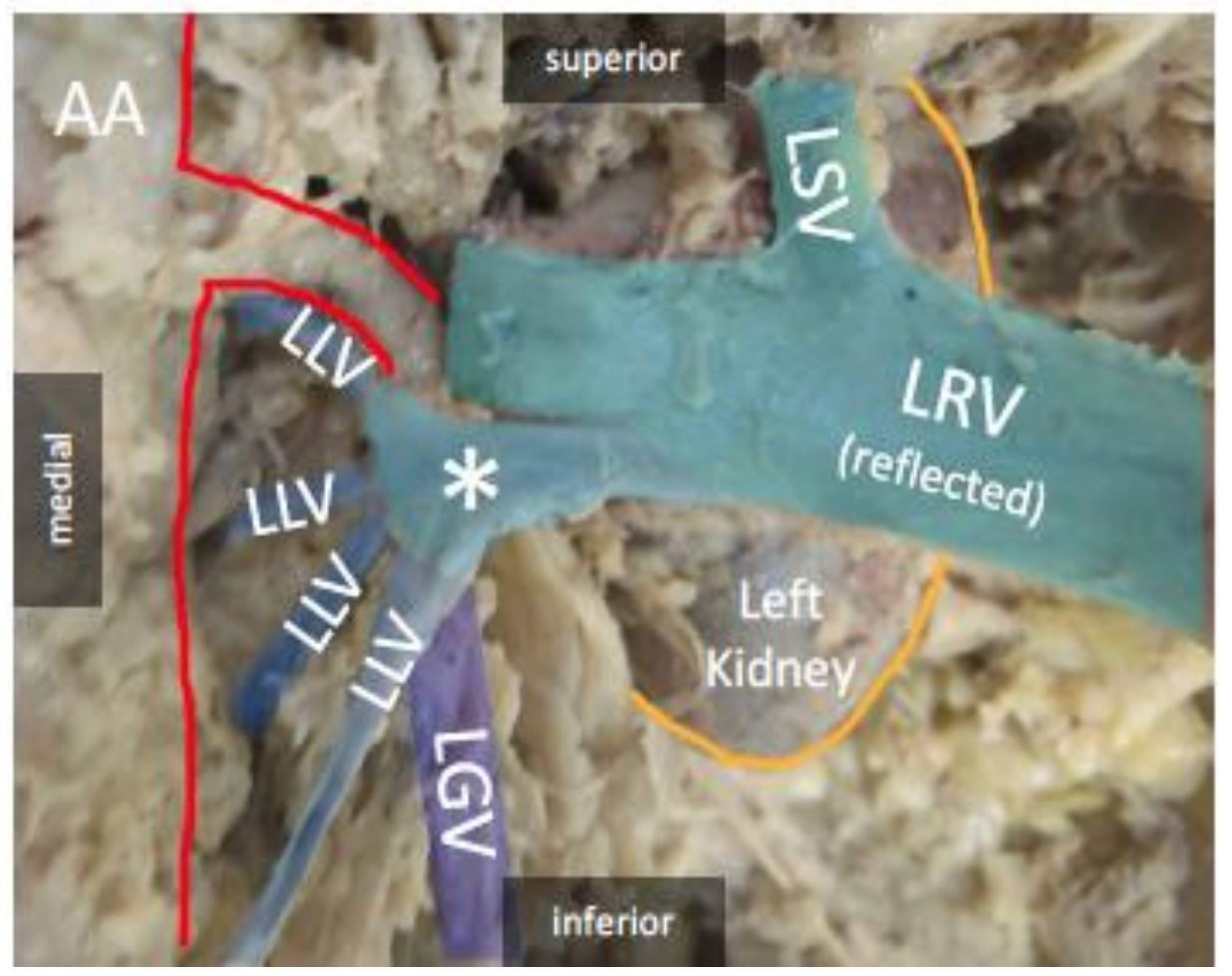

Figure 1: Annotated dissected specimen (anterior view with reflected LRV), showing an example of confluent trunk between LLV and LGV. AA abdominal aorta

*confluent trunk 
Figure 2
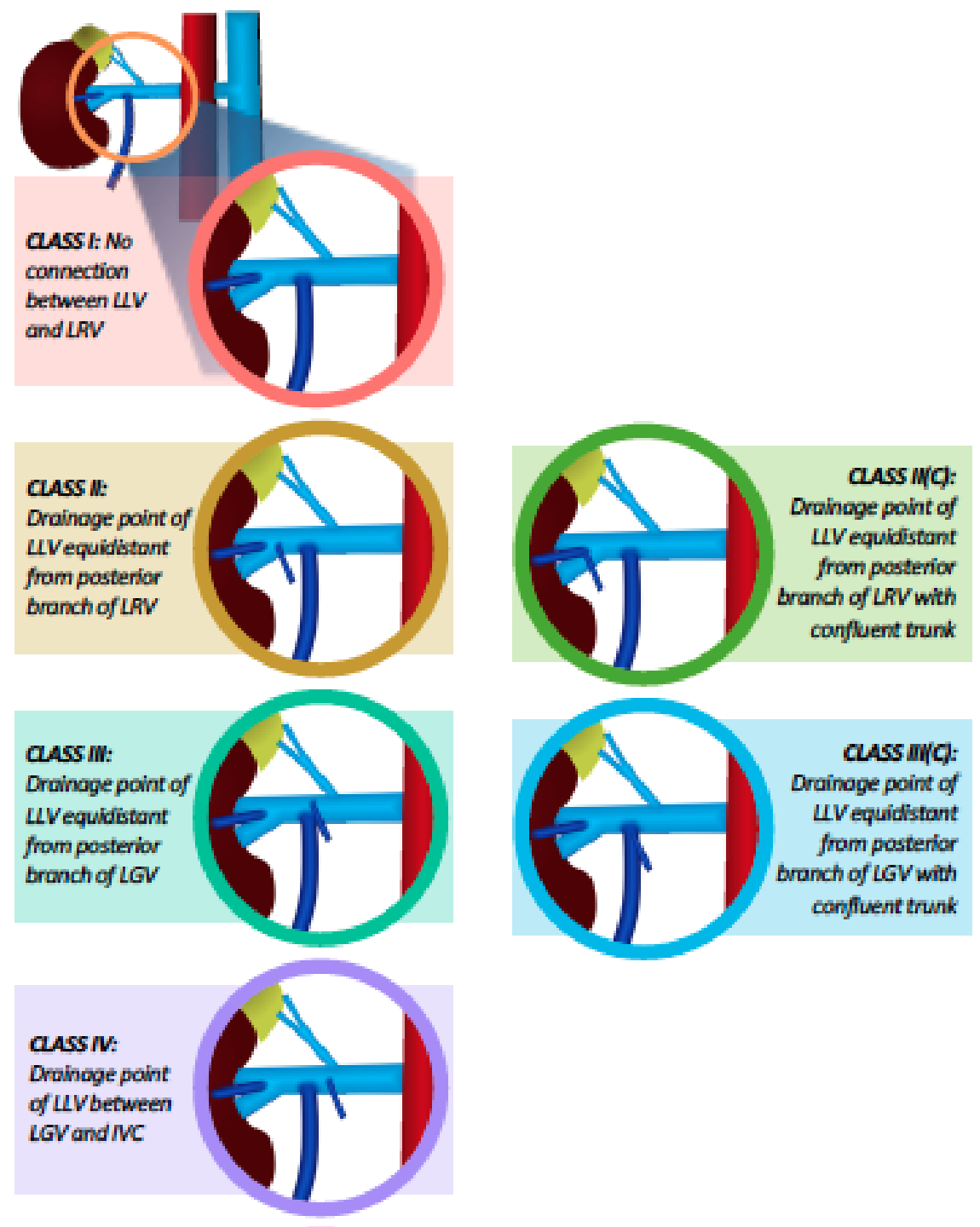

\section{cuss v:}

Confluence of LGV, LLV and posteriar branch of LRV

Figure 2: Illustrated classification, posterior view 


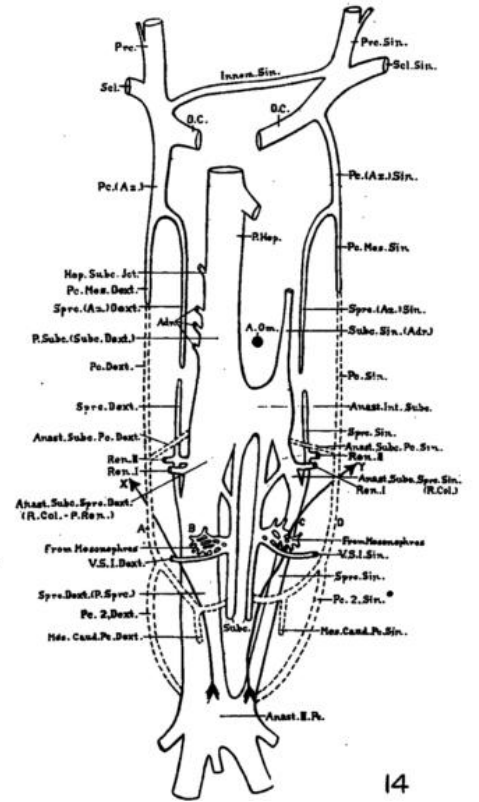

Figure 3: Diagram of the venous system of a 22-mm human embryo. From McClure et al, 1927. With permission from Wiley

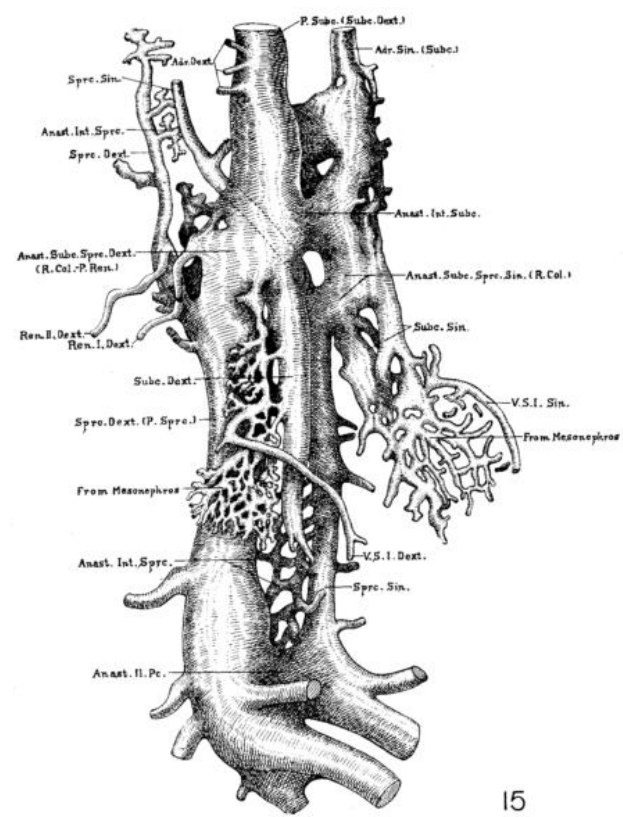

Figure 4: Reconstruction of the venous system of a 22-mm human embryo. From McClure et al, 1927. With permission from Wiley 